\title{
Estudos de três meios de cultura axênicos para a ferrugem das mirtáceas
}

\author{
Marilia Pizetta $^{1}$; Caroline Geraldi Pierozzi ${ }^{1}$; Gleice Viviane Nunes Pereira ${ }^{1}$, Juliana Cristina Sodário Cruz ${ }^{2}$; Christiane \\ Ceriani Aparecido ${ }^{3}$; Martha Maria Passador ${ }^{1}$; Edson Luiz Furtado ${ }^{1}$
}

${ }^{1}$ Departamento de Proteção Vegetal, Defesa Fitossanitária, Faculdade de Ciências Agronômicas - UNESP, Rua Doutor José Barbosa de Barros, ${ }^{\circ}$ 1780, CEP 18.610-307, Botucatu-SP, Brasil; ${ }^{2}$ APTA, Agência Paulista de Tecnologia do Agronegócio, Polo Centro Oeste, Av. Rodrigues Alves, 40-40, CEP 17.030-000, Bauru-SP, Brasil; ${ }^{3}$ Centro de Pesquisas e Desenvolvimento de Sanidade Vegetal, Instituto Biológico, Av. Cons. Rodrigues Alves, no 1252, CEP 04.014-002, São Paulo-SP, Brasil

Autor para correspondência: Marilia Pizetta (mapizetta@hotmail.com)

Data de chegada: 26/11/2015. Aceito para publicação em: 15/02/2016.

$10.1590 / 0100-5405 / 2145$

\section{RESUMO}

Pizetta, M.; Pierozzi, C.G.; Pereira, G.V.N.; Cruz, J.C.S.; Aparecido, C.C.; Passador, M.M.; Furtado, E.L. Estudos de três meios de cultura axênicos para a ferrugem das mirtáceas. Summa Phytopathologica, v.42, n.2, p.165-169, 2016.

O cultivo axênico apresenta-se como uma ferramenta importante para estudos relacionados à biologia, patogenicidade e manutenção de culturas puras de espécies biotróficas. Portanto, o presente trabalho objetivou analisar o crescimento in vitro de urediniósporos de Puccinia psidii, utilizando meios de culturas enriquecidos, que obtiveram êxito para o cultivo axênico de outras ferrugens. Componentes como sais, aminoácidos, carboidratos e vitaminas foram selecionados para o preparo de três meios de cultura enriquecidos: ASZV Kuck (10), SH Schenk \& Hildebrandt
(21) e HG Harvey \& Grasham (7), modificados. Comparativamente, elaboraram-se meios enriquecidos a partir de folhas de jambeiro (FJ), em quatro concentrações: 0,$5 ; 1,0 ; 3,0$ e 5,0 $\mathrm{g} \mathrm{L}^{-1}$ (gramas de folhas para cada litro de água destilada). Neste estudo foi constatado apenas o primeiro estágio de crescimento fúngico, crescimento dos tubos germinativos, não apresentando continuação no desenvolvimento do patógeno. Os meios de cultura enriquecidos que propiciaram maior crescimento do tubo germinativo de $P$. psidii foram os meios ASZV, HG e FJ na concentração $0,5 \mathrm{~g} \mathrm{~L}^{-1}$.

Palavras-chave: Puccinia psidii, Myrtaceae, cultivo de biotrófico.

\section{ABSTRACT}

Pizetta, M.; Pierozzi, C.G.; Pereira, G.V.N.; Cruz, J.C.S.; Aparecido, C.C.; Passador, M.M.; Furtado, E.L. Study of three axenic culture media for rust in Myrtaceae. Summa Phytopathologica, v.42, n.2, p.165-169, 2016.

Axenic cultivation has been shown as an important tool for studies related to the biology, the pathogenicity and the maintenance of pure cultures of biotrophic species. Therefore, the present study aimed to analyze the in vitro growth of Puccinia psidii uredospores, using enriched culture media that had success in the axenic cultivation of other rusts. Compounds such as salts, amino acids, carbohydrates and vitamins were selected for the preparation of three enriched culture media: ASZV Kuck (10), SH Schenk \& Hildebrandt (21) and HG Harvey \& Grasham (7), modified. Comparatively, enriched media were prepared from leaves of "jambeiro" (FJ) at four concentrations: 0.5 ; $1.0 ; 3.0$ and $5.0 \mathrm{~g} \mathrm{~L}^{-1}$ (grams of leaves per one liter of distilled water). In this study, verification covered only the first stage of fungal growth, germ tube growth, not continuing in the pathogen development. The enriched media that provided greater $P$. psidii germ tube growth were the media ASZV, HG and FJ at $0.5 \mathrm{~g} \mathrm{~L}^{-1}$ concentration.

Keywords: Puccinia psidii, Myrtaceae, biotrophic cultivation.

O fungo Puccinia psidii é um importante patógeno para as plantações de eucalipto e abrange uma gama de hospedeiros da família Myrtaceae, como o jambeiro, a goiabeira, a jabuticabeira, a melaleuca, entre outras mirtáceas nativas e exóticas (6). O cultivo axênico de fungos fitopatogênicos à plantas é considerado o primeiro passo para estudos mais detalhados das relações patógeno-hospedeiro (15).

O sucesso do cultivo axênico das Pucciniales deu-se a partir da década de 1950, cujo objetivo era entender os fatores responsáveis pelo parasitismo obrigatório desta ordem, utilizando-se meios de culturas enriquecidos, extratos vegetais e compostos suplementares de crescimento (4).

Desta forma, algumas espécies puderam ser cultivadas in vitro, como, Gymnosporangium juniperi virginianae $(4,9)$, Puccinia graminis f. sp. tritici (25), Puccinia graminis (12), Melampsora lini (23), Cronartium quercuum $\mathrm{f}$. sp. fusiforme (8), Phragmidium mucronatum
(19) e Phragmidium tuberculatum (18), Melampsora sp. (26) e Pucciniastrum sp. (27), Endocronartium harknessii (1), Peridermium pini (16), Cronartium flaccidum (13), Melampsora epitea (3), Melampsora larici-tremulae (14), Peridermium harknessii, Cronartium quercuum f. sp. banksinae e C. comandrae (24), Melampsoridium hiratsukanum (15).

Os componentes presentes nos meios de cultura enriquecidos têm a finalidade de imitar ou de se aproximar do efeito dos nutrientes químicos naturais presentes nas folhas das plantas, a fim de se obter um efeito semelhante de crescimento como aquele encontrado na natureza. O sucesso do cultivo axênico pode ser acompanhado baseando-se no trabalho de Kuhl et al. (11). Este artigo relata a elaboração de uma escala para cultivo axênico de espécies de Puccinia com base em estudos bem sucedidos realizados anteriormente pelos autores. A escala apresenta o desenvolvimento de um esporo até a formação de um micélio em meio 
de cultura enriquecido e, encontra-se dividida em quatro níveis: estágio de crescimento 0 - tubo germinativo ou hifa não ramificados; estágio de crescimento 1 - ramificação primária do tubo germinativo ou hifa; estágio de crescimento 2 - ramificações secundárias e terciárias das hifas saprofíticas; estágio de crescimento 3 - ramificações superiores, micélio visível a olho nu.

Pelo fato dos fungos biotróficos sobreviverem apenas em tecido vegetal vivo e da dificuldade para mantê-los em ambiente controlado cultivado em meios artificiais, informações essenciais sobre a biologia desses microrganismos, como estudos do ciclo biológico, variabilidade, testes de resistência clonal, entre outros, que auxiliam no manejo de doenças, estão restritos nas literaturas (2). A exemplo da ferrugem das mirtáceas, que infecta uma gama de hospedeiros, estudos biológicos do agente causal, considerando os hospedeiros alternativos, possuem relevância equivalente aqueles em plantas cultivadas, pelo fato dos urediniósporos infectarem plantas do mesmo gênero ou família (28).

Em eucalipto, a incidência de ferrugem ocorre, principalmente, em mudas em fase de viveiro e plantas em campo com até dois anos de idade e os danos ocasionados pelo patógeno resultam em atraso no desenvolvimento da planta e a perda de dominância apical (5), fatores consideráveis na produtividade de uma floresta. Devido à importância em se conhecer a biologia de P. psidii, para se conseguir um melhor manejo nas culturas que a hospedam, o objetivo do trabalho consistiu em averiguar o possível crescimento de urediniósporos desta ferrugem in vitro, fazendo a utilização de diferentes meios de cultura.

\section{MATERIAL E MÉTODOS}

O experimento foi conduzido na Fazenda Experimental Lageado, FCA-UNESP, Botucatu-SP, durante o período de março de 2011 à março de 2013. A coleta do material vegetal com os urediniósporos deu-se a partir de folhas de jambeiro. As folhas de jambeiro foram escolhidas como principal fonte de inóculo de urediniósporos de $P$. psidii por ser um hospedeiro universal da ferrugem, com produção de urediniósporos o ano todo comparando a mesma doença em eucalipto, cuja maior intensidade em campo abrange os meses de maio à agosto (22). As mudas de jambeiro doentes foram mantidas em casa de vegetação, como fonte de inóculo, a $25^{\circ} \mathrm{C}$ e irrigação controlada.

\section{Técnicas para isolamento dos urediniósporos}

Foram utilizadas duas técnicas para conseguir isolar os esporos de ferrugem em meio de cultura. Primeiro, utilizou-se o isolamento monospórico que consistiu em transferir um único urediniósporo de P. psidii, previamente germinado em ágar-água (AA), para o meio de cultura enriquecido e testemunha. Outra técnica adotada consistiu na transferência de uma porção de urediniósporos para o meio de cultura enriquecido e testemunha AA, supondo que o desenvolvimento dos urediniósporos de $P$. psidii não ocorreriam com esporos únicos e precisariam do estímulo de outros urediniósporos para se desenvolverem. Para isso, foram transferidos cerca de 20 esporos para cada placa, ainda não germinados, com o intuito de observar a ocorrência de algum estímulo no crescimento do patógeno.

Diante da dificuldade para o isolamento do patógeno em meio de cultura pelas técnicas anteriores, foi utilizada a técnica de suspensão de urediniósporos em meio de cultura, com a finalidade de obter dados referentes ao percentual de germinação e crescimento do tubo germinativo, podendo comparar a eficácia dos meios de cultura destacando aquele mais apropriado para o desenvolvimento de $P$. psidii in vitro.

\section{Meios de Cultura Enriquecidos}

Os meios de cultura axênicos utilizados foram ASZV Kuck (10) modificado por Carvalho Jr. et al. (3), que foi utilizado para o cultivo axênico de Melampsora epitea, ferrugem do chorão; o meio enriquecido SH Schenk \& Hildebrandt (21) modificado por Moricca \& Ragazzi (13), utilizado para o cultivo axênico de Cronartium flaccidum, ferrugem do pinus e o meio axênico HG Harvey \& Grasham (7) modificado por Pei \& Pawsey (17), Pei \& Gibbs (16) e Moricca \& Ragazzi (13), utilizado para o cultivo de Cronartium ribicola, Peridermium pini e Cronartium flaccidum, ferrugens do pinus.

$\mathrm{O}$ pH da solução nutritiva ASZV foi ajustado para 6,0 e, em seguida, submetida a uma esterilização através de uma pré-filtragem em membrana de polietileno com porosidade de $0,45 \mu \mathrm{m}$ e de outra filtragem em membrana de polietileno com porosidade de $0,22 \mu \mathrm{m}$. A solução nutritiva foi acrescentada ao meio de cultura AA estéril $2 \%$ a 60 ${ }^{\circ} \mathrm{C}$, sendo a mistura distribuída em placas de Petri de $6 \mathrm{~cm}$ de diâmetro. $\mathrm{O} \mathrm{pH}$ dos meios enriquecidos $\mathrm{SH}$ e $\mathrm{HG}$ foi ajustado para 5,7-5,8, respectivamente. Em seguida, os meios foram autoclavados a $120^{\circ} \mathrm{C}$ por 20 minutos e distribuídos em placas de Petri de $6 \mathrm{~cm}$ de diâmetro.

Para todos os meios de cultivo enriquecidos foram avaliadas duas concentrações, sendo uma de $50 \%$ de solução nutritiva na proporção $1: 1$ (meio axênico: meio ágar-água) e outra concentração de $80 \%$ de solução nutritiva na proporção 4:1 (meio axênico: meio ágar-água). Devido a esterilização dos componentes do meio de cultura ASZV ocorrerem pelo método de filtração em membranas, a concentração dos nutrientes estaria em parte diluída ao acrescentá-los ao meio AA esterilizado, por isso, foram preparadas soluções nutritivas em diferentes concentrações, sendo o mesmo princípio tratado para os meios de cultura SH e HG.

Além dos meios de cultura enriquecidos também foram elaborados meios de cultura contendo extrato de folhas de jambeiro (FJ), a fim de proporcionar condições naturais mais próximas as do hospedeiro. Portanto, para a elaboração dos meios de cultura com extrato de FJ, fez-se a coleta das folhas mais jovens da planta (até o terceiro par de folhas) as quais são mais suscetíveis à doença. Estas folhas foram pesadas em balança para o ajuste em quatro concentrações 0,$5 ; 1,0$; 3,0 e 5,0 $\mathrm{g} \mathrm{L}^{-1}$ de água destilada, essas concentrações basearam-se no teor de sacarose presente em todos os meios de cultura enriquecidos.

Em seguida, as folhas foram trituradas em liquidificador contendo um litro de água destilada estéril até obter uma solução uniforme, que permaneceu em fervura por cinco minutos a fim de que os compostos das folhas fossem transferidos para esta solução. Posteriormente, a solução foi filtrada através de papel filtro, repetindo-se o processo três vezes. Após a filtragem, foi acrescentado ágar-água e, esta foi autoclavada a $120{ }^{\circ} \mathrm{C}$ por 20 minutos e distribuída em placas de Petri de $6 \mathrm{~cm}$ de diâmetro. $\mathrm{O}$ meio de cultura padrão AA foi utilizado como testemunha.

Após o preparo dos meios, os urediniósporos foram coletados das folhas de jambeiro através de uma agulha histológica estéril e suspensos em solução salina $0,8 \%$ autoclavada. Desta suspensão, foram depositados $20 \mu \mathrm{L}$ em cinco placas de Petri nos meios de cultura AA e enriquecidos ASZV, SH, HG e FJ contendo cinco réplicas (gotas de suspensão) para cada placa. Após a absorção total da parte líquida da suspensão dos meios AA e enriquecidos, as placas foram vedadas e acondicionadas em câmara de temperatura controlada B.O.D. a 21$22{ }^{\circ} \mathrm{C}$, correspondente a temperatura média mais adequada (3) sem fotoperíodo, para proporcionar a germinação dos esporos de ferrugem.

\section{Características avaliadas}

As características avaliadas foram a percentagem de germinação e o crescimento do tubo germinativo. A variável germinação dos 
urediniósporos foi avaliada após 24 horas da deposição dos esporos em meio de cultura sob microscópio óptico. Foram considerados germinados, os esporos que apresentaram crescimento do tubo germinativo igual e/ou superior ao tamanho do esporo. O experimento foi composto de cinco repetições para cada tratamento, contendo cinco réplicas para cada repetição. Em cada réplica foram contados 100 esporos, separando-os em germinados e não germinados.

A avaliação do crescimento do tubo germinativo foi realizada após 24, 48 e 72 horas da deposição dos esporos nos meios de cultura. Foram utilizadas cinco repetições para cada tratamento, contendo cinco réplicas para cada repetição, sendo medidos quatro esporos para cada réplica. As medições dos tubos germinativos foram realizadas através do Software EDN-2 em $\mu \mathrm{m}$ (micrômetro).

Os resultados foram analisados pelo Teste Scott-Knott, a 5\% de probabilidade.

\section{RESULTADOS E DISCUSSÃO}

\section{Técnicas para isolamento dos urediniósporos}

Os resultados obtidos para a técnica de cultivo axênico monospórico, nos diferentes meios de cultura testados, não permitiram comparar o percentual de germinação e o crescimento do tubo germinativo, sendo possível verificar uma estagnação no desenvolvimento do tubo germinativo após a transferência de um único urediniósporo já germinado para o meio de cultura enriquecido. Isso pode ter provocado um estresse no esporo coletado, devido à mudança de ambiente, isto é, de um meio de cultura para outro, que pode ter causado essa paralisação no crescimento. No que se refere à transferência de vários urediniósporos para os meios de cultura, também não foram registrados resultados significativos.

As técnicas utilizadas para a transferência de urediniósporos de ferrugem para o meio de cultura enriquecido diferem entre os estudos. Carvalho Jr. et al. (3) transferiram os urediniósporos de Melampsora epitea, retirados das pústulas, com o auxílio de uma agulha histológica. Moricca \& Ragazzi (13) depositaram os urediniósporos de Cronartium flaccidum através de um pincel e, com a ajuda da circulação de ar presente na câmara de fluxo laminar, os esporos eram depositados nas placas de Petri, em diferentes densidades. Moricca \& Ginetti (15) utilizaram discos de folhas de almieiro, previamente esterilizadas e infectadas com Melampsoridium hiratsukanum, sendo anexados às tampas da placa de Petri, através de uma fita dupla-face, com o princípio da ejeção natural dos urediniósporos no meio de cultura. Com isso, além do ajuste das concentrações dos componentes presentes no meio de cultura, o conhecimento sobre os métodos de inoculação é imprescindível para o estabelecimento inicial das primeiras colônias.

Para a obtenção dos dados referentes a percentagem de germinação e crescimento do tubo germinativo, procedeu-se a utilização da técnica de suspensão de urediniósporos em meio de cultura.

\section{Características avaliadas}

O meio de cultura ASZV, nas concentrações 50\% e 80\%, não interferiu na germinação dos urediniósporos, ambos com percentagem inferior à testemunha (Tabela 1). Apesar da diferença estatística significativa, os valores foram próximos, com variação de $6 \%(46,56 \%$, $44,84 \%$ e $40,32 \%$ para os meios AA, ASZV 50\% e ASZV $80 \%$, respectivamente). O percentual de germinação para o meio de cultura $\mathrm{SH}$, nas duas concentrações, não diferiu da testemunha com variação menor de $1 \%$ entre os tratamentos $(46,6 \%$ para AA, $45,44 \%$ para o meio SH $50 \%$ e $46,12 \%$ para SH $80 \%$ ). O mesmo foi observado para o meio de cultura axênico HG (42,96\% para o AA, 43\% para o HG $50 \%$ e $43,04 \%$ para o HG $80 \%$ ) (Tabela 1 ).

Meios de cultura com extrato de folhas de jambeiro (FJ) diferiram da testemunha AA $(41,12 \%)$, porém não diferiram entre si, sendo $48,52 \%$ FJ $0,5 \mathrm{~g} \mathrm{~L}^{-1}, 48,48 \%$ FJ $1,0 \mathrm{~g} \mathrm{~L}^{-1}, 48,64 \%$ FJ $3,0 \mathrm{~g} \mathrm{~L}^{-1}$ e 49,96\% FJ 5,0 $\mathrm{g} \mathrm{L}^{-1}$. Essas evidências permitiram observar que mesmo ocorrendo variações entre o percentual de germinação de urediniósporos de $P$. psidii (6\% para o meio de cultura ASZV e, aproximadamente, $9 \%$ para

Tabela 1. Percentagem de germinação dos urediniósporos e crescimento do tubo germinativo de Puccinia psidii do jambeiro em diferentes meios de cultura. ASZV - meio de cultura axênico ASZV, SH - meio de cultura axênico Schenk \& Hildebrandt, HG - meio de cultura axênico Harvey \& Grasham, 50\% e 80\% - percentagens da solução nutritiva de meio axênico, FJ - meios de cultura enriquecidos com folhas de jambeiro.

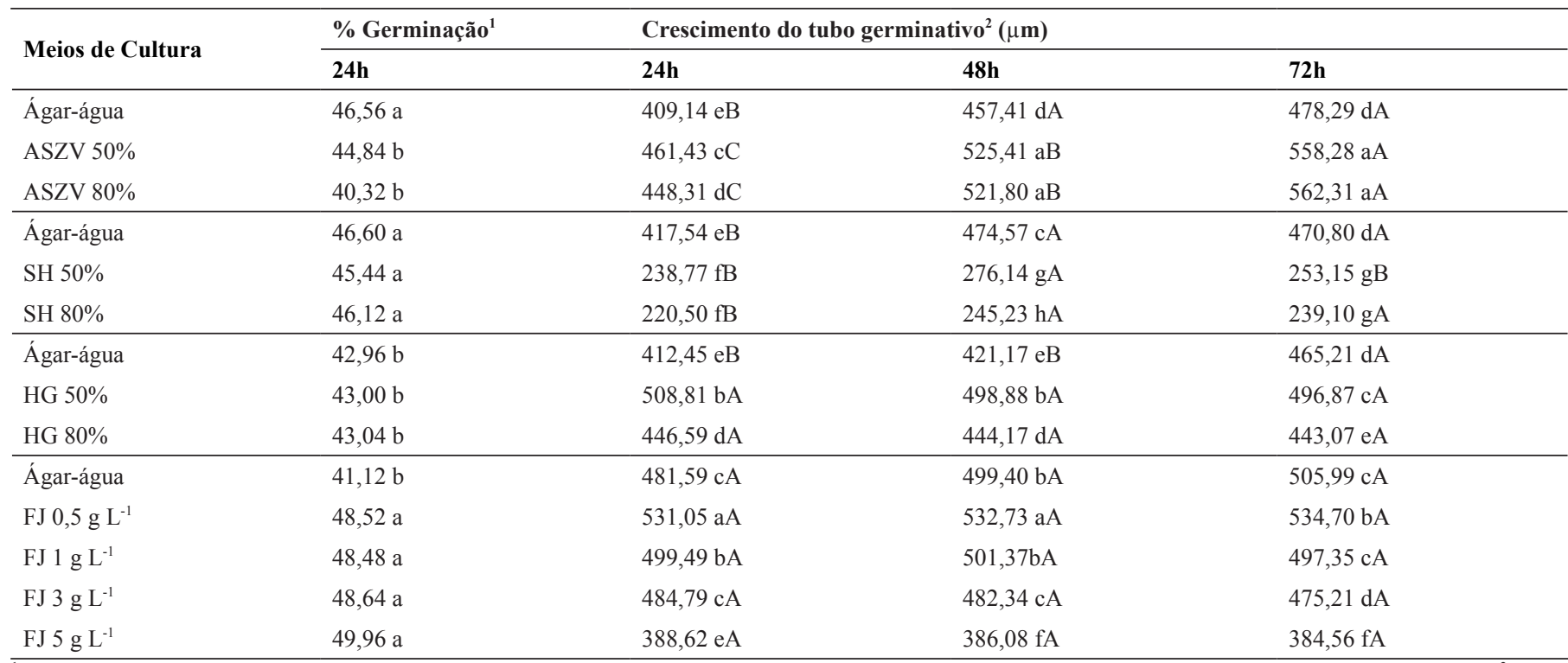

${ }^{1}$ Média de 25 repetições. As médias seguidas pela mesma letra não diferem estatisticamente entre si pelo teste de Scott-Knott ao nível de 5\%. CV: $13,46 \%$. ${ }^{2}$ Média de 100 repetições. As médias seguidas pelas mesmas letras minúsculas nas colunas e maiúsculas nas linhas não diferem estatisticamente entre si. Teste de ScottKnott ao nível de 5\%. $\mathrm{CV}_{24 \mathrm{~h}}: 20,89 \%$; $\mathrm{CV}_{48 \mathrm{~h}}: 19,14 \%$; $\mathrm{CV}_{72 \mathrm{~h}}: 17,98 \%$ (vertical). CV: $16,78 \%$; CV: $18,67 \%$; CV: 16,83\%; CV: 14,29\%; CV: 26,99\%; CV: 21,52\%; CV: 25,92\%; CV: 22,13\%; CV: 25,96\%; CV: 16,01\%; CV: 14,75\%; CV: 15,63\%; CV: 16,37\%; CV: 18,96\% (horizontal). 
o meio de cultura FJ), não foi possível determinar um meio de cultivo axênico enriquecido adequado e que estimule a germinação de $P$. psidii em condições artificiais. Em doze meios de cultura axênicos diferentes utilizados para o crescimento de $M$. hiratsukanum, a germinação variou 36\%, após $48 \mathrm{~h}$ de incubação, visto que os menores valores percentuais foram encontrados para aqueles meios axênicos que não proporcionaram o crescimento dessa ferrugem (15).

O crescimento dos tubos germinativos de Puccinia psidii nos meios de cultura ASZV foi superior à testemunha nos três momentos avaliados. Nos meios de cultura ASVZ 50\% e ASZV 80\%, o crescimento do tubo germinativo apresentou uma atividade acelerada, mantendo-se constante até o terceiro dia avaliado. Isso permitiu observar que, para esta variável, o meio de cultura enriquecido ASZV proporcionou o aumento do crescimento do tubo germinativo.

O meio de cultura $\mathrm{SH}$, a $50 \%$ e $80 \%$, proporcionou crescimento inferior à testemunha AA de 46,2\% e 49,2\%, respectivamente no último dia avaliado. Esse decréscimo pode ter ocorrido devido à riqueza nutritiva dos meios de cultura, podendo interferir no desenvolvimento do patógeno. Para o meio de cultura HG na concentração 50\% obtevese crescimento do tubo germinativo superior a testemunha. Já na concentração $80 \%$ este crescimento foi inferior ao AA. Ágar-água obteve resultado semelhante aos demais controles, mas HG 50\% e 80\% estabilizaram o crescimento logo no primeiro dia.

Os resultados para os meios de cultura FJ foram distintos entre os tratamentos. Estes meios nas concentrações 1,0 e 3,0 g $\mathrm{L}^{-1}$ apresentaram resultados próximos aos da testemunha nos dois primeiros dias avaliados, sendo que os tratamentos com FJ 3,0 $\mathrm{g} \mathrm{L}^{-1}$ proporcionou crescimento inferior à testemunha e à concentração 1,0 $\mathrm{g} \mathrm{L}^{-1}$ no terceiro dia. Em FJ 5,0 $\mathrm{g} \mathrm{L}^{-1}$ foram observados os menores crescimentos dos tubos germinativos durante o período de avaliação (23,9\% inferior à testemunha) e na concentração $0,5 \mathrm{~g} \mathrm{~L}^{-1}$ observou-se o maior crescimento do tubo germinativo (10,3\% superior ao AA em 24h). Desta maneira, a atividade bioquímica das folhas, em grandes concentrações, pode ter causado efeito inibitório no metabolismo da germinação do patógeno.

Estes resultados permitiram concluir que os meios de cultura enriquecidos ASZV, HG e FJ estimularam o crescimento do tubo germinativo de Puccinia psidii, com destaque para o ASZV 50\% e 80\%, $\mathrm{HG} 50 \%$ e FJ $0,5 \mathrm{~g} \mathrm{~L}^{-1}$. Na avaliação do crescimento do tubo germinativo de Puccinia triticina após 24 horas de incubação dos esporos, Reis \& Richter (20) observaram diferenças no crescimento do tubo entre os meios de cultura, com o meio de cultura frutose-ágar resultando no menor crescimento, $9,6 \mu \mathrm{m}$ ( $41 \%$ inferior à testemunha) e o meio de cultura com infusão de folhas de trigo-ágar, o maior crescimento $(52,03$ $\mu \mathrm{m})$. Estes foram os mesmos meios de cultura que apresentaram menor e maior percentual de germinação, respectivamente.

Segundo a escala para cultivo axênico de espécies de Puccinia (11), foi verificado apenas o primeiro estágio da escala (estágio de crescimento 0 ), não tendo continuidade no desenvolvimento de Puccinia psidii em meio de cultura enriquecido artificialmente. De acordo com Scott \& Maclean citado por Kuhl et al. (11), a fase de transição entre um urediniósporo germinado para um micélio implica em uma mudança na expressão genômica da ferrugem, com consequente reorientação do metabolismo e, dentre aqueles esporos que tiveram o crescimento saprofítico iniciado, apenas uma pequena parte sobrevive, tornando-se colônias visíveis. Uma das razões, sugerida pelos autores, seria a adaptação do metabolismo das hifas desenvolvidas para as condições atuais impostas pelo meio de cultura enriquecido e as tentativas frustradas para o cultivo axênico, em partes, poderia ser sustentada pela falta de controle sobre esse processo de transição.

É importante ressaltar que o elevado teor de nutrientes pode afetar no crescimento do patógeno em meio de cultura artificial. O aumento da concentração da solução nutritiva nos meios de cultura enriquecidos de $50 \%$ para $80 \%$ não se mostrou significativo para as variáveis estudadas (percentagem de germinação e crescimento do tubo germinativo).

Em suma, pode-se inferir que, dos meios testados neste estudo, não há um meio de cultura ou um método de inoculação padrão para se cultivar $P$. psidii em meio artificial. Estudos mais detalhados são necessários para o ajuste da técnica de cultivo axênico do agente causal da ferrugem das mirtáceas. Kuhl et al. (11), afirmaram que algumas espécies de ferrugem podem ser mais facilmente cultivadas que outras e destacaram pontos importantes, como o estudo das necessidades nutricionais do patógeno, bem como, os métodos de inoculação e a densidade ideal de esporos, que devem ser levados em consideração para o sucesso do cultivo axênico de ferrugens.

\section{Agradecimentos}

Os autores agradecem ao Professor Salvatore Moricca pelas valiosas informações sobre cultivo axênico de Pucciniales, a FAPESP pelo apoio financeiro (Processo 11/04423-8), ao CNPq e a CAPES.

\section{REFERÊNCIAS}

1. Allen, E.A.; Blenis, P.V.; Hiratsuka, Y. Axenic culture of Endocronartium harknessii. Mycologia, Lawrence, v.80, n.1, p.120-123, 1988.

2. Aparecido, C.C. Estudos ecológicos sobre Puccinia psidii Winter-ferrugem das mirtáceas. 2001. 66f. Dissertação (Mestrado em Fitopatologia)-Faculdade de Ciências Agronômicas, Universidade Estadual Paulista “Júlio Mesquita Filho, Botucatu.

3. Carvalho JR. A.A.; Martins, E.M.F.; Figueiredo M.B. Cultura axênica de Melampsora epitea, ferrugem do chorão (Salix babylonica), a partir de urediniósporos. Fitopatologia Brasileira, Brasília, v.23, n.3, p.379-385, 1998.

4. Cutter JR., V.M. Studies on the isolation and growth of plant rusts in host tissue cultures and upon synthetic media I. Gymnosporangium. Mycologia, Lawrence, v.51, p.248-295, 1959.

5. Ferreira, F.A. Ferrugem do eucalipto. Revista Árvore, Viçosa, v.7, p.91-109, 1983.

6. Furtado, E.L.; Marino, C.L. Eucalyptus rust management in Brazil. Forest Research, New Zealand, v.16 (suppl.), p.118-124, 2003.

7. Harvey, A.E.; Grasham, J.L. Axenic culture of the mononucleate stage of Cronartium ribicola. Phytopathology, Saint Paul, v.64, n.7, p.1028-1035, 1974.

8. Hollis, C.A.; Schmidt, R.A.; Kimbrough, J.W. Axenic culture of Cronartium fusiforme. Phytopathology, Saint Paul, v.62, n.12, p.1417-1419, 1972.

9. Hotson, H.H.; Cutter Jr., V.M. The isolation and culture of Gymnosporangium juniperi-virginianae Schw. Proceedings National Academy of Sciences of the United States of America, Washington DC, v.37, n.7, p.400-403, 1951.

10. Kuck, K.H. Über die infektionsbedingte Veränderungen der Aminosäuren und Fettsäuren in Puccinia graminis f. sp. tritici, Rasse 32, infizierten Weizenblättern und die "in vitro" Sporulation des Pilzes. 1979. Ph.D Thesis. Rheinisch- Westfälischen Technischen Hochschule, Aachen.

11. Kuhl, J.L.; Maclean, D.G.; Scott, K.J.; Williams, P.G. The axenic culture of Puccinia species from uredospores, experiments on nutrition and variation. Canadian Journal of Botany, Ottawa, v.49, p.201-209, 1971.

12. Maclean, D.J. Axenic culture and metabolism of rust fungi. In: Scott, K.J.; Chakravorty, A.K. The rust fungi. Saint Paul: Academic Press, 1982, p. 37-120

13. Moricca, S.; Ragazzi, A. Axenic culture of the aecial state of Cronartium flaccidum from Italy. Mycological Research, Cambridge, v.98, p.125862, 1994.

14. Moricca, S.; Ragazzi, A.; Longo, B.N. In vitro growth of the aspen rust Melampsora larici-tremulae. Mycological Research, Cambridge, v.104, p.1250-1257, 2000 . 
15. Moricca S.; Ginetti B. Saprophytic growth of the alder rust fungus Melampsoridium hiratsukanum on artificial media, Fungal Biology, Manchester, v.119, n.7, p.568-579, 2015.

16. Pei, M.H., Gibbs, J.N. Axenic culture of Peridermium pini from single aeciospores. Plant Pathology, London, v.41, n.1, p.91-94, 1992.

17. Pei, M.H.; Pawsey, R.G. Axenic culture of Peridermium pini. Mycological Research, Cambridge, v.95, p.108-115, 1990.

18. Rahbar Bhatti, M.H. Axenic culture of rose rust fungus, Phragmidium tuberculatum. Canadian Journal of Botany, Ottawa, v.62, n.5, p.10981099, 1984.

19. Rahbar Bhatti, M.H., Shattock, R.C. Axenic culture of Phragmidium mucronatum. Transactions of the British Mycological Society, Cambridge, v.74, n.3, p.595-600, 1980

20. Reis, E.M.; Richter, R.L. Efeito de substratos sobre a germinação de uredosporos e comprimento de tubos germinativos de Puccinia triticina. Fitopatologia Brasileira, Brasília, v.32, p.75- 78, 2007.

21. Schenk, R.U.; Hildebrandt, A.C. Medium and technique for induction and growth of monocotyledonous and dicotyledonous plant cell cultures. Canadian Journal of Botany, Ottawa, v.50, p.199-204, 1972.

22. Takahashi, S.S.; Furtado, E.L.; Camargo, F.R.A.; Ramiro, G.A. Teste de modelo para estimativa da incidência e evolução da ferrugem do eucalipto, Puccinia psidii Winter, em duas regiões de plantio no Estado de São Paulo. In: International Congress and Exhibition on Forest, 5., 1999, Curitiba. Forest 99: resumos. Rio de Janeiro: Biosfera, 1999. 1 CD-ROM.

23. Turel, F.L.M. Saprophytic development of the flax rust Melampsora lini, race $n^{\circ}$ 3. Canadian Journal of Botany, Ottawa, v.47, n.5, p.821-823, 1969.

24. Walla, J.A. Axenic culture of Peridermium harknessii, Cronartium quercuum f.sp. banksianae and Cronartium comandrae. Forest Research, (Suppl.) p.33-43, 2003.

25. Williams, P.G.; Scott, K.J.; Kuhl, J.L. Vegetative growth of Puccinia graminis f. sp. tritici in vitro. Phytopathology, Saint Paul, v. 56, p.1418-1419, 1966

26. Yamaoka, Y.; Katsuya, K. Axenic culture of four Melampsora species parasitic on willows. Transactions Mycological Society of Japan, Hiroshima, v. 25, p. $85-92,1984$

27. Yamaoka, Y.; Katsuya, K. Axenic culture of Pucciniastrum agrimoniae, $P$. boehmeriae and $P$. coryli. Transactions Mycological Society of Japan, Hiroshima, v. 28, p. 155- 161, 1987.

28. Yamaoka, Y. Recent outbreaks of rust diseases and the importance of basic biological research for controlling rusts. Journal of General Plant Pathology, Tokyo, v.80, p. 375-388, 2014. 